\title{
EdUCACIÓN Y SEXUALIDAD, UNA PROPUESTA PARA PENSAR SUS VÍNCULOS
}

\section{Education and Sexuality, a Proposal to Think their Links}

\author{
http://doi.org/10.33255/25914669/581
}

\begin{abstract}
Gisela Manzoni
ICentro Interdisciplinario de Investigaciones en Género - Instituto de Investigaciones en Humanidades y Ciencias Sociales Universidad Nacional de La Plata - Consejo Nacional de Investigaciones Científicas y Técnicas - Universidad Nacional de La Plata

giyitan@yahoo.com.ar https://orcid.org/0000-0002-3776-6523
\end{abstract}

\begin{abstract}
Adriana Valobra
Centro Interdisciplinario de Investigaciones en Género - Instituto de Investigaciones en Humanidades y Ciencias Sociales Universidad Nacional de La Plata - Consejo Nacional de Investigaciones Científicas y Técnicas - Universidad Nacional de La Plata

profeindiva@gmail.com https://orcid.org/0000-0003-3955-4791
\end{abstract}

Recibido: 15 de mayo de 2021

Aceptado: 7 de junio de 2021

\section{Resumen}

En este artículo, nos proponemos introducir la temática de la Educación Sexual Integral en ciencias sociales a través de dos recorridos. Primero, abordaremos la relación entre género y ciencia desde los aportes que ha realizado la teoría feminista. Luego, enfocaremos en la relación entre sexualidad y educación. No nos proponemos exhaustividad en un campo como éste, de creciente producción, sino, más bien, brindar algunas claves para un recorrido que, a la vez que repone algunas cuestiones temáticas, puede ser útil como primera instancia de inmersión para quienes se acercan al tema. 
Palabras clave: Género - Educación Sexual Integral - Ciencias Sociales Argentina

\section{Abstract}

In this paper, we propose to introduce the theme of Integral Sexual Education in social sciences in two ways. One, we will approach the relationship between gender and science from the contributions that feminist theory has made. Another, we will focus on the relationship between sexuality and education. We do not propose exhaustiveness in a field of increasing production, but offering some keys for a tour that, once it answers some thematic questions, may be useful to those who begin to approach the subject.

Keywords: Gender - Comprehensive Sexual Education - Social Sciences

- Argentina 


\section{Primeras palabras ${ }^{1}$}

En octubre de este año, 2021, se cumplen en la Argentina quince años de la sanción de la Ley Nacional de Educación Sexual Integral (ESI) 26.150. Este hecho que constituye, sin lugar a dudas, un hito en la imbricada relación entre sexualidad y educación, no es el inicio de ese complejo vínculo. Históricamente, la sexualidad ha sido y es parte de la educación, un lazo constitutivo. Aun cuando se negara su ligazón, las instituciones educativas, formales y no formales, estuvieron y están profundamente atravesadas por constructos y relaciones de género que son parte constitutiva de su estructura. La creación, el ejercicio y la modificación de reglamentos que normaron y norman la vestimenta, la conducta, el lenguaje e -incluso- la vida por fuera de las instituciones son ejemplo de ello. Prácticas, intervenciones e interacciones propias de la vida en las instituciones educativas que recrean, reproducen y subvierten relaciones de género desiguales. Por otra parte, la currícula, expresa o implícitamente, evidencia la dimensión sexual de los contenidos que también se expresa en la selección y perspectivas que subyacen a la enseñanza de ellos. ${ }^{2}$

Quienes ejercimos la docencia antes de la sanción de esta ley sabemos que en la escuela ocurren diversas situaciones: amores y desamores, embarazos deseados y no deseados, abortos clandestinos e inseguros, así como redes para hacer esos mismos abortos más seguros. Conocemos historias de estudiantes que huyen al descubrir un embarazo. Advertimos la desesperación de jóvenes que van a ser padres y no saben cómo podrán sostener económicamente a su hijx, porque no consiguen trabajo, como la mayoría de las personas de su edad en esta parte del mundo. Entre colegas, familiares y amigues, desarrollamos redes para buscar cunas, leche en polvo, ropa 0 una garrafa. Sabemos lo que es dar clases con bebés en el aula. También y lamentablemente muchas veces fuimos testigos de la deserción escolar entre las chicas que atraviesan embarazos no deseados y de la enorme vulnerabilidad a la que están expuestas las infancias y las juventudes.

Quienes ejercemos la docencia antes y después de esta ley, también sabemos lo difícil que sigue siendo enseñar en el aula temáticas vinculadas con el cuidado del cuerpo, con la prevención de Infecciones de Transmisión Sexual y embarazos, con la detección de abusos y la desnaturalización de las violencias por razones de género

1 Agradecemos la lectura atenta y los generosos comentarios a Moira Severino, Mariela Sarlinga y Magdalena Tirabassi. Para este escrito, hemos retomado como insumo las clases de cursos virtuales dictados en la Universidad Nacional de Quilmes (2009 y 2011) -subidas al campus para orientar al estudiantado de la Maestría en Ciencias Sociales-, en instancias de formación docente en cursos de ADULP, así como en grado en la UNLP, entre otras.

2 Tomaz Tadeu da Silva (1999) problematiza la idea de currículo y sus significados como artefactos de género. 
o identidad sexual -cuando muchas veces, nuestrxs estudiantes o nosotrxs mismxs podríamos contar relatos en primera persona-.También sabemos que para muchxs estudiantes la escuela es un lugar seguro, donde transitar con cierta libertad deseos e identidades elegidas.

Quienes ya transitamos unos años en la docencia, recordamos a estudiantes que no participaban de las charlas de educación sexual porque no lograban manejar el estrés que podían conllevar esos diálogos, pero, sobre todo, porque sus familias no autorizaban esa participación. Conocimos lo que era lidiar con equipos directivos reacios a trabajar estos temas. Y sabemos de la responsabilidad que nos generaba abordarlos, de las dudas por tener la información precisa -con tal falencia nos han formado a nosotras mismas en la escuela, en la casa, en la vida-. Y, sobre todo, sabíamos de la empatía e implicación que necesitábamos construir con nuestrxs estudiantes.

Nuestros cuerpos e identidades, como parte de ese gran conjunto que es el cuerpo docente, experimentan las curiosidades de estudiantes, compañerxs y directivos sobre la "sexualidad atrapada de la señorita maestra" (Fernández, 1992): si somos solteras, si tenemos novio o novia, si tenemos uno o más a la vez, si nos besamos, si vivimos en la misma casa, si nos casamos... Sabemos que, al enterarse del embarazo de sus maestras o profesoras, muchas veces se terminan las preguntas y empiezan los sobreentendidos -o todo lo contrario-, y también descubrimos que se intrigan cuando no tenemos hijxs. Comprendemos la importancia de armar redes, de trabajar con otres, de generar acuerdos para sortear resistencias y de tener con quien debatir y hacer una "vigilancia epistemológica" de nuestras prácticas, puesto que trabajar con la sexualidad implica revisar constantemente nuestras propias miradas del mundo, nuestras visiones sobre la sexualidad de otras generaciones, sobre nuestros sentires y vivencias personales. Claro que estas cuestiones no comienzan con la ley de ESI: la sexualidad estuvo y está en las salas de los jardines, en las aulas y los pasillos de todos los niveles educativos porque la sexualidad forma parte de nuestras vidas y porque toda educación, además de ser política, es sexual. ${ }^{3}$

Lo que la ley de ESI efectivamente nos trajo fue ante todo un marco legal, pedagógico y curricular desde donde actuar. Nos trajo, también, la posibilidad de exigir al Estado materiales, recursos y capacitación. Esta ley comenzó a ordenar y hacer visible situaciones y saberes que ya eran parte de la escuela, corrió el velo de la "clandestinidad" en la que muchas veces se enmarcaban nuestras prácticas y nos quitó, a lxs educadorxs, algunos temores. La ESI es un derecho para lxs estudiantes y una obligación para lxs docentes. Asimismo, para muchxs docentes este marco legal

3 La frase "Toda educación es sexual" se ha convertido en una de esas consignas que logran sintetizar luchas, debates y posicionamientos epistemológicos, así como décadas atrás lo hizo "Toda educación es política". Hace diez años, Graciela Morgade -referente en educación y sexualidad y, también, en ESI- coordinó una compilación que lleva por nombre Toda educación es sexual. Hacia una educación sexuada justa, texto que sienta posicionamiento cuando hacemos referencia a esta frase 
es también un derecho que tenemos el orgullo de haber conquistado. ${ }^{4}$ La ESI nos ha dado derecho a enseñar, derecho a exigir seguir aprendiendo y, también, legitimidad para transitar las instituciones con nuestros cuerpos e identidades abyectas, no sin dudas, pero sí con pasos más firmes. La ESI vino a confirmar que la dimensión sexual es parte del carácter político de la educación.

El dossier que aquí presentamos retoma un camino que otras colegas allanaron y nos inscribimos en la valoración de sus sustantivos aportes. ${ }^{5}$ Para introducirnos en estos temas, abordaremos, primero, la relación entre género y ciencia desde los aportes que ha realizado la teoría feminista. Luego, enfocaremos en la relación entre sexualidad y educación. No nos proponemos exhaustividad en un campo como éste, de creciente producción, sino, más bien, brindar algunas claves para un recorrido que, a la vez que repone algunas cuestiones temáticas, puede ser útil como primera instancia de inmersión para quienes se acercan al tema.

\section{Feminismo, género y ciencia}

La educación moderna, asentada sobre bases racionalistas, convirtió a las instituciones educativas en templos del saber. En la Argentina, por ejemplo, las leyes que organizaron el sistema educativo a fines del siglo XIX resaltaron su carácter universal, gratuito y laico. Sin embargo, estos avances en la materia se desarrollaron desde un paradigma cientificista y positivista reforzaron los estereotipos del sexismo y el determinismo biologicista que primaban en la sociedad patriarcal de ese período. En este primer apartado, organizaremos los ejes para pensar el tema en torno a los aportes de Frances Olsen sobre los estereotipos del sexismo y el determinismo biologicista, la sexualización y jerarquización de un conocimiento elaborado sobre una pauta prescriptiva invisibilizada y la transmisión del conocimiento a través de una educación que reproduce la sexualización y la jerarquización. ${ }^{6}$

Adrienne Rich retoma a Kathleen Gough para pensar las características del poder masculino que se repiten en las sociedades arcaicas y en las contemporáneas. Dos de ellas son la "obstaculización de su creatividad" y el "arrebato" de amplias áreas del conocimiento social y sus logros culturales. Este descubrimiento significó un punto clave de las luchas por los derechos de las mujeres y el reclamo de la

\footnotetext{
4 Además de la perspectiva de derechos, la ESI contempla, entre otras, la perspectiva de género, la perspectiva feminista y de diversidad; miradas que abonan una ruptura con el modelo binarista y biomédico. Estas y otras perspectivas conviven y debaten dentro de un enfoque transversal, generando múltiples tensiones y resistencias.

5 Insistimos en la dificultad de la exhaustividad en los aportes desde distintas áreas disciplinares, por lo que remitimos apenas a algunos trabajos del campo de las ciencias sociales. Cfr. Elizalde, Felitti y Queirolo (2009), Seoane y Severino (2019), González del Cerro (2020), Severino y Dappello (2019), Faur (2020) y, asimismo, las producciones del grupo Mariposas Mirabal (2019). 
modificación del sexismo en el dominio del saber. Las referentes más importantes de la Edad Contemporánea en la lucha por el acceso de las mujeres a la educación y al conocimiento son, a la vez, las que se consideran las primeras líderes inscriptas en el feminismo: Olympe de Gouges, en Francia, y Mary Wollstonecraft, en Inglaterra (Abbate, 2020). Ambas reivindicaron, además, la igualdad en materia de derechos políticos, civiles y sociales. La obra de la segunda ha planteado lo que se denomina el dilema Wollstonecraft, el cual señala las incoherencias que implica la demanda de igualdad en un contexto patriarcal en el cual "igualdad" remite, precisamente, a una categoría masculinizada (Pateman, 1992, p. 20). En todo caso, como ha señalado Joan Scott (2002), las paradojas son constitutivas de la intervención política del feminismo.

Sus notables alegatos a favor de los derechos femeninos y en defensa de la capacidad de las mujeres para acceder a la educación quedaron sepultados bajo los estudios frenológicos que, en nombre de la ciencia positiva, intentaron justificar en el siglo XIX los preconceptos de género respecto de que el lugar de las mujeres era el hogar y la maternidad. Para ello, se midieron, capciosamente, los cráneos y los cerebros para concluir que los femeninos no tenían suficiente capacidad para

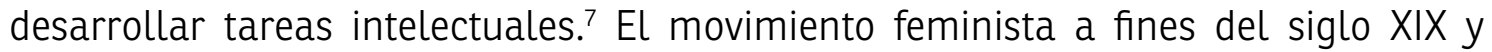
principios del XX rebatiría esas postulaciones y pondría el acento en la necesidad de igualar a las mujeres en derechos al permitir el acceso parejo a la educación y la ciencia, que se veían como causas de la situación de minusvalía en la que se encontraban las mujeres. Es interesante consignar también cómo muchas de esas ideas se reactualizan en torno a los discursos de las neurociencias, que alcanzan gran éxito en el plano educativo actualmente pero que no recapacitan sobre las reposiciones del biologicismo y sexismo (Ciccia, 2018).

Conforme avanzaba el siglo XX, la lucha que individual y colectivamente realizaron muchas mujeres en distintas disciplinas y ámbitos nacionales llevó a que fuera más difícil su exclusión de la educación e, incluso, se hizo necesario reconocer sus aportes al conocimiento científico. Según la abogada Frances Olsen, en términos conceptuales, esa exclusión de las mujeres del ámbito de lo racional -que aún persiste- tiene que ver con el modo en que se estructuró el pensamiento liberal clásico y occidental, en general, en pares duales, tal como expusimos previamente.

Uno de los aportes fundamentales de la discusión entre feminismo y ciencia lo ha realizado la física norteamericana Evelyn Fox Keller. En su obra Reflexiones sobre género y ciencia parte de la pregunta ¿en qué medida está ligada la naturaleza de la ciencia a la idea de masculinidad y qué podría significar que la ciencia fuera distinta? Asimismo, la autora plantea que un estudio sobre la relación entre género y

7 Para un análisis de esas investigaciones y una crítica véase Gómez Rodríguez (2005). 
ciencia no está implicando sólo a las mujeres, sino que involucra a los varones que, retomando la expresión de Simone de Beauvoir, se hacen y no nacen, tanto como las mujeres. Según Fox Keller, género y ciencia son categorías construidas socialmente, creadas por fuerzas cognitivas, emocionales y sociales que se dan en relaciones sociales complejas. Su objetivo es, entonces, revisar la conjunción histórica entre ciencia y masculinidad, a la vez que la disyunción, también histórica, entre ciencia y feminidad (Fox Keller, 1991, p. 28). La autora retoma las ideas de Thomas Khun sobre la lucha por la hegemonía de un paradigma respecto de otro e intenta identificar las fuerzas políticas y sociales que afectaban el desarrollo del conocimiento científico. Así, señala la importancia del sexismo. Fox Keller cuestiona el dualismo que opone lo emocional y lo intelectual. Según la autora, implica una creencia acerca de que existe una división intelectual del trabajo según la cual la razón que domina la ciencia está estrechamente conectada con el ideal de masculinidad con el que compartiría las características de impersonal, racional y general.

La reconocida física y teórica feminista esboza un programa a fin de identificar esas divisiones duales en la estructura básica de la ciencia y la sociedad moderna. Según su teoría, es necesario analizar las raíces, las desviaciones y las consecuencias de la red interactiva de asociaciones y disyunciones relacionadas con el sistema género ciencia y explicar cómo se relaciona la ideología con el género-ciencia, cómo se distribuyen las relaciones sociales y cómo afecta a varones y a mujeres la relación con la ciencia y la naturaleza. Su método rechaza los dualismos. Fox Keller produce su teoría a la luz de uno de los postulados más caros del feminismo, "Lo personal es político", que fue el primer gran cuestionamiento a la dicotómica escisión entre público y privado. Fox Keller propició la ruptura del esquema cuando incluyó lo personal, asignado por la teoría liberal al mundo de lo privado, en la política referente al espacio público. Utilizando esa idea, Fox Keller sostiene que, si lo personal es político, lo científico es personal y que, por tanto, es político. En tanto personal y político, exige un reposicionamiento del pensamiento de las mujeres en el universo de la ciencia y destaca el valor de lo personal en la construcción del conocimiento.

Por lo tanto, su propuesta señala la necesidad de otear las dimensiones personal, emocional y sexual de la construcción y aceptación de las afirmaciones del conocimiento científico tanto en relación a lo femenino como lo masculino. De este modo, desmitifica la creencia de una ciencia impersonal en la que la idea de que cuanto menos personal sea una investigación, más científica resultará. En este sentido, la propuesta de Fox Keller empalma con la de otras autoras que coinciden en que la mirada desde las mujeres permite una revisión de los basamentos de la ciencia. Según sintetiza Mabel Alicia Campagnoli (2018):

"Estas posturas epistemológicas feministas contribuyeron a resignificar el ideal científico de objetividad (Yanes Abreu, 2012) aportando respectivamente críticas a 
los sesgos androcéntricos (Longino, 1997), desarrollos de la noción de experiencia (Harding, 1986) y del valor de los conocimientos situados (Haraway, 1991)" (p. 1).

Desde estas perspectivas, se requiere conectar lo científico y lo extracientífico y las relaciones intra y extracomunidad. Concluye que, si su condición de mujer fue una fuerte causa de marginación en el campo científico, el feminismo le permitió explotar ese estatus como un privilegio desde el cual enriquecer su práctica como cientista, a fin de ofrecer un nuevo modo de mirar los problemas. En ese caso, Donna Haraway ha planteado que el reconocimiento de la subjetividad del sujeto cognoscente implica el primer ejercicio de objetividad científica, aunque se trata de un nuevo tipo de objetividad distinta de la planteada por el positivismo. De ese modo, siguiendo la lógica expuesta, el reconocimiento del sujeto situado no quita mérito a la construcción científica que produce, sino que se validan los saberes situados, al reconocer que el sujeto cognoscente produce desde un punto de vista (Haraway, 1993).

Frances Olsen ha propuesto que el pensamiento occidental se estructuró en torno de esquemas duales, binarios o pares opuestos: racional-irracional, activo-pasivo, cultural-natural, universal-singular, entre otros. El primer término de cada par se ha adjudicado, con una jerarquía superior, a lo masculino; mientras se ha ubicado al segundo término como inferior y asociado a lo femenino. Según Olsen, la sexualización del dualismo piensa en términos binarios de masculino y femenino; la jerarquización eleva lo masculino y la supuesta descripción de lo correcto en términos de género es, en realidad, una prescripción disimulada. Así, por ejemplo, la masculinidad se construye sobre ciertas exigencias de control emocional, pero se presentan como si fueran naturalmente innatas (Olsen, 1990).

La biología ha contribuido a construir y asentar criterios sexistas y racistas, al otorgarles un supuesto basamento científico. Desde los campos de la biología y la psicología, Richard Lewontin, Steve Rose y Leon Kamin (1987), consignan que el determinismo biológico empieza citando la supuesta evidencia: "Los hechos" de la diferencia entre varones y mujeres. Se considera que estos hechos dependen de tendencias psicológicas anteriores que se explican por las diferencias biológicas del cerebro y las hormonas. En general, ese determinismo establece que las diferencias humanas de comportamiento entre varones y mujeres encuentra un paralelismo en las sociedades no humanas, lo que les aporta una aparente universalidad que no puede ser negada simplemente deseando que la sociedad sea más justa. El arraigo biologicista de estas pautas apenas se disimula en las analogías del comportamiento humano con el de los animales, el cual:

"Intenta persuadirnos de la universalidad de sus afirmaciones. Si existe en los seres humanos la dominación masculina es porque también se da entre los mandriles, los leones, los patos... La bibliografía etiológica está repleta de 
ejemplos de mandriles que 'cuidan de su harén', de leones macho con dominio de `su’ orgullo, de ánades reales que `estupran` en cuadrilla y de colibríes que `se prostituyen'." (p. 192)

De este modo, se:

"Proyectan forzadamente en los animales cualidades humanas, y pretende encontrar posteriormente que la conducta de estos animales refuerza la expectativa de una 'naturalidad' de la condición humana (...)" (pp. 192-193).

Finalmente, el determinismo establece que las diferencias de sexo surgen por selección natural, consecuencia de diferentes papeles biológicos de los sexos en la reproducción. Rose, Kamin y Lewontin se proponen analizar la estructura y las falacias de las investigaciones de los deterministas biológicos que intentan mostrar al patriarcado como simple reflejo de alguna subyacente necesidad biológica. Sostienen que:

"Aunque las diferencias de sexo están determinadas por las hormonas, no son una consecuencia de las actividades de hormonas solamente masculinas o femeninas, sino más probablemente de las fluctuantes diferencias en las proporciones de estas hormonas y de sus interacciones con los órganos receptores (...) por supuesto, también las hormonas son generadas por procesos iniciados a partir de genes, pero están mucho más sujetas a una modificación del medio ambiente o a una manipulación deliberada" (pp. 184-185).

Estos estudios evidencian que el punto no es la existencia o inexistencia de diferencias entre las personas sino analizar cuál es el sentido político que se construye alrededor suyo.

El siglo XIX y principios del XX habían mostrado las obsesiones médico clínicas respecto de la "indefinición" genital, pero las limitaciones técnicas para operar un cambio en esa circunstancia habían colocado al tema en la patologización y criminalización o, en el mejor de los casos, en manos del psicoanálisis que trataría de "operar" la adaptación de la identidad psicológica a la biológica (Ben, 2000). Verena Stolke sintetiza el modo en que el desarrollo de la cirugía en las décadas de 1950 y 1960 permitió el establecimiento de las primeras clínicas de cambio de sexo en Estados Unidos. En el entendimiento de que había un sexo cromosomático o genital que no necesariamente representaba la identidad de género -socialmente constituida-, se intervino a la persona para reasignarle el sexo que supuestamente le correspondía a esa identidad. Stolke señala la persistencia de la visión binaria y la idea de correspondencia sexo-género que subsistía en estas prácticas (Stolke, 2006). En línea con los planteos de esta autora, estudios recientes han evidenciado 
el papel de los laboratorios en la construcción de marcadores de género, así como el desarrollo de una medicalización en la temática, aunque incluyen también matices sobre los límites de esa apuesta (Rustoyburu y Eraso, 2018).

La identidad, como esencia biológica, ha sido largamente cuestionada por el feminismo, que se resistió a la idea la biología como destino (aunque algunas líneas ponderaron y ponderan un sujeto político anclado en esa biología, exaltando, más que cuestionando, los valores asociados históricamente a ella mientras que otras, retoman lo biológico desde miradas críticas alternativas al constructivismo social) (Guerra y Sciortino, 2013; Ariza, 2018). La noción de género sirvió para romper con esos conceptos. Asimismo, en las ciencias sociales, el concepto de género tuvo un intento de visibilizar los aspectos relacionales de la opresión femenina respecto de la masculina y fue particularmente útil como estrategia de ingreso en el mundo académico, pero no menos en el político, donde se lograron importantes avances a partir de su utilización (Femenías, 2008). Según Isabel Moránt (2018):

"La publicación de El segundo sexo, en 1949, en la conocida editorial Gallimard, debía de producir un escándalo, inesperado, en la sociedad francesa del momento (...) debía de abrir una brecha en el conocimiento sobre la condición y la situación de las mujeres, que, más tarde, podría servir para la renovación de la teoría y de la práctica política del feminismo que resurgiría en los años setenta" (p. 1).

La divulgación de esta obra tuvo diversos derroteros a lo largo de distintas geografías (Smaldone, 2020) pero, en conjunto, como ha señalado la historiadora alemana Gisela Bock (1991), se intentaba romper con el estático molde de lo biológico que suponía la dicotomía entre sexo (biología)/género (social), como si fuera parte de la discusión naturaleza-cultura, un nuevo binarismo que no contemplaba las interrelaciones entre esas partes.

Entre los aportes a la reflexión sobre el concepto de género, sin duda, Marta Lamas y Joan Scott son referentes que no sólo repasaron el uso del mismo, sino que hicieron aportes teórico metodológicos. Lamas (1986), desde la antropología, puso en cuestión la pregunta subyacente en los estudios antropológicos:

"¿Hay o no hay una relación entre la diferencia biológica y la diferencia sociocultural? Esta pregunta cobraba un cariz político del que la antropología no podía sustraerse, sobre todo cuando todo un movimiento social también se lo preguntaba. ¿Si los papeles sexuales son construcciones culturales, por qué siempre las mujeres están excluidas del poder público y relegadas al ámbito doméstico? ¿Y si los papeles sexuales son determinados biológicamente, qué posibilidades hay de modificarlos? El nuevo feminismo lo formuló acertadamente ¿por qué la diferencia sexual implica desigualdad social?" (p. 177). 
Al hacerlo, señala Lamas, el feminismo marcó el "problema político que subyace a toda la discusión académica sobre las diferencias entre hombres y mujeres" ( $p$. 178). Scott (1996) por su parte, desde la historia, avanzó en las dimensiones del concepto (simbólica, normativa, institucional y subjetiva) para incorporar una mirada relacional con estrecha vinculación con una concepción sociohistórica que considera a los sujetos no como un ex ante, sino como un constructo singular de las relaciones sociales en un momento histórico determinado que oblitera concepciones binarias y biologicistas. Apenas dos referencias para considerar una trama de disciplinas que se entrelazan en la construcción del conocimiento. Como ha señalado Eileen Boris (2020):

"Tanto la historia de las mujeres cuanto los estudios de las mujeres se sometieron a influencias intelectuales más generales, tales como el género en tanto que categoría de análisis, los estudios interdisciplinarios y críticos sobre raza, el postmodernismo y el giro lingüístico, los estudios culturales, el poscolonialismo, el transnacionalismo y la globalización. Ambos campos se han movido desde las mujeres como entidad fáctica hacia el género como significante de relaciones de poder, y ninguno de ellos ha abandonado totalmente a las mujeres como esencia corporizada y simbólica, aunque la transición de la historia social hacia los estudios culturales haya significado que a veces no se trabaje con la categoría 'mujeres' sino con feminidades y masculinidades, lo femenino y lo masculino, y el género como productor de pliegues en lo híbrido" (p. 49).

Los estudios feministas consignaron la dominación masculina, así como la existencia de un modelo de masculinidad heterosexual fue cuestionado desde la teoría queer. Asimismo, en épocas más recientes se desarrolló un campo específico que adoptó la denominación de "men's studies", que analiza las claves específicas de la construcción de la masculinidad. Si bien a lo largo del tiempo los vaivenes han sido muchos, en líneas generales la mayoría de estas investigaciones tiende a cuestionar las posiciones de poder y privilegio y ha generado una práctica política en la que distintos grupos de varones intentan demostrar que se puede construir una masculinidad alternativa a la dominante. Para hacerlo, estos estudios promueven desmontar las nociones de masculinidad existentes para luego propiciar una reconstrucción. La historiadora y filósofa francesa Elizabeth Badinter (1993) sintetiza los cambios en las nociones de masculinidad:

"Si la masculinidad es algo que se aprende y se construye, también puede cambiar. En el siglo XVIII, un hombre digno de ese nombre podía llorar en público y ruborizarse; a fines del siglo XIX, eso mismo podría llevarlo a perder la dignidad masculina" (pp. 54-55). 
Es decir que no sólo la feminidad es históricamente construida, sino que también la masculinidad requiere una historización, regionalización y especificación cultural para comprender el pluralismo de masculinidades (Mosse, 1997). Algunos estudios, ahora clásicos, contribuyeron a ese ejercicio de desmonte conceptual con el que es necesario iniciar. Un texto clave fue el que teorizó la masculinidad hegemónica. Según Raewyn Connell (1997):

"Se puede definir como la configuración de práctica genérica que encarna la respuesta corrientemente aceptada al problema de la legitimidad del patriarcado, la que garantiza (o se toma para garantizar) la posición dominante de los hombres y la subordinación de las mujeres" (p. 39).

Esta definición señala, asimismo, la necesaria connivencia de una serie de dinstituciones sociales, donde la escuela tiene un papel significativo, que tienen poder para lograr la dominación y la subordinación. Connell, además, señala que ello no implica que todos los varones actúen en correspondencia con ese modelo, pero son sus cómplices obtienen los "dividendos patriarcales" que resultan de "aquella ventaja que obtienen los hombres en general de la subordinación de las mujeres" (p. 4l). Según Michael Kimmel (1997), especialista estadounidense:

"El mercado es donde se verifica y prueba la virilidad, se trata por lo tanto de un escenario 'generizado', en el cual se cargan de significado las tensiones entre hombres y mujeres y entre distintos grupos de hombres. Estas tensiones sugieren que las definiciones culturales de género son puestas en escena en un terreno en disputa y son, en sí mismas, relaciones de poder" (p. 50).

Entre los caracteres más marcados de una masculinidad hegemónica construida sobre patrones de inequidad se resalta la violencia y el uso y el dominio de los elementos para ejercerla por parte de los varones. Esa violencia involucra una serie de aspectos que no se reducen a lo material, sino que alcanzan a lo simbólico, lo psicológico, etcétera (Segato, 2003).

Una segunda característica es que la masculinidad está asociada a la inexpresividad de los sentimientos (Kimmel, 1997) y a una reafirmación violenta que opera no sólo en la relación con las mujeres sino, también, entre pares (Segato, 2003). Si bien estos patrones se modificaron en las últimas décadas, el modelo sigue operando. Asimismo, la visión del varón como un ser hormonal, libidinal, se arrastra desde el siglo XIX en que alcanzó su máxima expresión en el discurso nacionalista-imperialista sustentado en la medicina como disciplina científica legitimante. En ella, el modelo heterosexual se impone y constituye al varón en oposición a la mujer y, además, su propia identidad implica un rechazo a lo femenino que incluso puede rayar en la misoginia, aunque ésta nunca debe confundirse con la homofobia, el otro elemento 
constitutivo de la masculinidad.

Como sintetiza Kimmel (1997):

"La definición hegemónica de la virilidad es un hombre en el poder, un hombre con poder, y un hombre de poder. Igualamos la masculinidad con ser fuerte, exitoso, capaz, confiable, y ostentando control" (p. 51).

Según Michael Kaufman (1995), ese poder tiene una contracara combinación de poder y privilegios con dolor, aislamiento y alienación. Sin desconocerlo, los alcances de sus efectos no son equiparables a los que infringe la violencia contra las mujeres o translesbohomoodio que se habilita como característica propia de la definición de la masculinidad. En el marco de estos debates, e intentando profundizar una línea no punitivista, también desde la ESI se está intentando generar líneas de trabajo en torno a las masculinidades.

Desde la década de 1990, el feminismo discute los pares dicotómicos y evidencia su escaso alcance para analizar la complejidad del género. Es decir, discute la dicotomía y la sexualización, rompe con los estereotipos (Maffía, 2008, p. 5). Según Diana Maffía y Mauro Cabral (2003), en ello:

"Hay un profundo asunto ideológico, que antes creíamos limitado a que la dicotomía anatómica se trasladaba a la 'atribución de género' (el género que los otros en el mundo social nos adscriben, masculino o femenino), a la 'identidad de género' (el propio sentido de pertenencia a la categoría femenina o masculina) y al 'rol de género' (las expectativas culturales sobre las conductas apropiadas para una mujer 0 un varón). Pero estamos ante el disciplinamiento quirúrgico de la misma base material sobre la cual los roles de género se inscriben" (p. 88).

También señalan que, en los últimos años, ha surgido un movimiento político de género que combate la medicalización y demanda que las cirugías infantiles sean suspendidas pues entienden que no es la persona la que debe adaptarse a los imperativos sociales, sino que es la sociedad la que debe modificar sus ideas reduccionistas y aceptar las diferencias. En ese sentido, Cabral advierte que los conceptos como transgénero, transgeneridad y transgenérico/a, en una acepción amplia:

"Incluyen en su enunciación a todas aquellas personas que, de modos diversos, contradicen la relación congruente y necesaria entre corporalidad, deseo e identidad y expresión de género asociada con el binarismo sexual heteronormativo occidental" (Cabral, 2007, p. 325).

En ese caso, la idea se resume en géneros múltiples/cuerpos contingentes. Sin embargo, estos desarrollos se presentan en términos educativos con distintos énfasis, como veremos a continuación. 


\section{Educar la sexualidad}

En este segundo apartado, recorreremos el modo en que la educación sexual fue ocupando un lugar en la agenda pública que, en particular, intentaba modificar los modos en que se encontraba en ella como disciplinamiento de los cuerpos con base en silencios y omisiones o expresando pautas represivas y excluyentes. En ese sentido, proponemos considerar qué se entiende actualmente por Educación Sexual Integral en el marco de la legislación en Argentina y en conexión con marcos geográficos más amplios.

Para Michael Foucault (1991) desde el siglo XVII y hasta fines del siglo XIX, se da un proceso de construcción de las categorías de género modernas en Occidente caracterizado por la represión sexual y corporal, aunque ello, sin embargo, conllevó una multiplicación de discursos sobre lo que se pretendía reprimir (p. 20). Al señalar un momento específico para la aparición de esa sexualidad, emparentada con el capitalismo, Foucault cuestionó la inmutabilidad de aquellas figuraciones a la vez que describió cómo se habían ido pautando (Ben, 2020). Aunque la sexualidad no puede definirse como meramente genital, algunas interpretaciones sugieren que se figuró un modo en que el cuerpo encapsulaba la sexualidad y estrechaba la asociación de los sujetos a lo natural, de manera que lo biológico se convirtió en una metáfora de los símbolos socioculturales que encarnaban el cuerpo y la sexualidad (Le Breton, 2002). Algunos consideraron que su obra sobredimensionó los discursos del poder y le dio a las prescripciones un alcance que habría que moderar (Giddens, 1992). ${ }^{8}$ Sin embargo, no se cuestionó la existencia de aquellos modelos "ortopédicos".

El surgimiento de la sexología como disciplina científica ejemplificaría la necesidad de limitar una "normalidad" de las relaciones sexuales y la represión de lo que se alejaba de ellos (Laqueur, 2003). A través de ella se diseñaron varios dispositivos específicos para el disciplinamiento y se caracterizó por delimitar lo que era esperable para cada sexo. Según Peter Gay (1984), un conocido médico sostenía, en referencia a cierta apetencia sexual desenfrenada, "Lo que en los hombres son por hábito, las mujeres lo son sólo por excepción". Las mujeres no podían tener otro destino que un asilo de dementes si en la obsesiva taxonomía decimonónica eran catalogadas como "ninfómanas" u otras "desviaciones". Por el contrario, los varones con tales caracteres eran lo esperable y, si carecían de esas pulsiones exacerbadas, ello se disimularía en el matrimonio pues en la mujer dominaba la anestesia sexual, particularmente en las casadas (Gay, 1984, p. 144).

8 Anthonny Giddens (1992) señala que los mismos juicios analizados por Foucault sobre acusados del delito de ciertas prácticas sexuales son, al mismo tiempo, ejemplo de normalización como de infringir aquellas normas. Por su parte, Peter Gay (1984), a través de una serie de documentos tales como epistolarios, señaló que, en plena era victoriana, la experiencia sexual estaba lejos de apegarse a lo que la norma imponía. Una interesante relectura de Foucault que contextualiza su obra sin buscar un todo coherente en ella, Cfr. Ben (2020). 
Hacia el siglo XIX, se cristalizó una idea acerca de la sexualidad de la mujer y la represión de sus apetencias sexuales como fenómenos de manifestación de insania mental (Gómez Rodíguez, 2005). Asimismo, el surgimiento de la sexología como disciplina científica a fines del XIX y principios del XX tuvo particular interés en las conductas "desviadas" por lo que aparece la noción de patología sexual y sus posibles tratamientos (González García, 2005). ${ }^{9}$ En ese sentido, se consideraba que los deseos de unas mujeres por otras generaban una masculinización que devenía, supuestamente, de formas genitales anatómicamente inadecuadas que se conocieron como "patología del clítoris" tal como el megaclítoris o suponían que la afección era el hermafroditismo. En este camino surgió la idea de un tercer sexo. ${ }^{10}$

La clitoridectomía, intervención quirúrgica para eliminar el órgano de placer sexual femenino, era una respuesta para convertir a las mujeres en dóciles reproductoras (Iglesias Aparicio, 2003). La práctica persistió en Estados Unidos y en otros ámbitos hasta entrados la década de 1940 y se extendió para curar la masturbación femenina y las prácticas consideradas "contranatura" como el lesbianismo (Ramaciotti y Valobra, 2008).

Las implicancias de aquellos modelos tuvieron como consecuencia el privilegio normativo del modelo heteronormativo que, además, instó a constituir subjetividades y prácticas jerarquizadas entre los sexos. Ello significó que el modelo hegemónico (construido por médicos, legistas y políticos, entre otros) se diera en una matriz heterosexual. La maternidad constituyó a la mujer en las tareas reproductivas y la vinculó al varón con el fin de la "reproducción de la especie" en términos raciales mejorados, según las expectativas de los discursos darwiniano y eugénico surgidos a fines del siglo XIX."11

Esta pareja heterosexual, reconocida como "la normalidad", también facilitó la identificación, por negación, de las conductas sexuales "desarregladas", "desviadas" o, como se las llamó frecuentemente, "pervertidas". Las diferencias anatómicas entre los sexos incidían en el comportamiento social de las personas y todo aquel comportamiento sexual por fuera de la norma era considerado "anormal", "patológico" y digno de ser modificado a partir de supuestos consejos y tratamientos "científicos". En pos de "modelar" la costumbre individual, estos tratamientos traerían beneficios a la sociedad en cuanto al caudal y la calidad del potencial reproductivo y en la

9 Así, la histeria era asociada a una falta de relaciones sexuales, pero somatizada como agresividad en el carácter, mientras la neurastenia era una manifestación pasiva (vértigo, dolores de cabeza) del mismo fenómeno. Una preocupación creciente generó la ninfomanía que encontró como "cura" la ovarotomía, que implicaba la castración; práctica que se popularizó.

10 Un desarrollo de ésta y otras teorías en Fiocchietto (1987), especialmente el capítulo "La interpretación organicista del lesbianismo".

11 Sobre darwinismo y eugenesia en la Argentina, véase Miranda y Vallejo (2005) y Palma (2005). 
eliminación del "mal ejemplo".

Las llamadas perversiones eran el opuesto a la modelización hegemonizante de matriz heterosexual. Se consideraban perversiones cuando el acto sexual se realizaba con un fin distinto al de la procreación. Estos trabajos tenían impacto en aspectos legales y políticos los cuales daban sustrato legal y judicial. La homosexualidad era vista por muchos como una perversión. En su raíz etimológica, "homo" estaba relacionado al concepto griego de igual -distinto del concepto romano de "homo" como hombre, varón-. Presentaba, entonces, una doble carga. Es decir, no sólo que en ella la reproducción era imposible, sino que, además, implicaba una relación donde las partes no eran "complementarias" en el sentido del binarismo varón-mujer que se presentaba en el modelo heterosexual.

Aunque sus teorías también configuraban el pensamiento normativo y heterosexual, la línea psicoanalítica inaugurada por Sigmund Freud (1856-1939), a principios de siglo, así como las ideas del inglés Henry Havelock Ellis (18591939) contribuyeron, según Giddens, a la declinación en Europa de la idea del homosexualismo como perversión.

El concepto "der Homosexuelle" fue acuñado en 1869 por el escritor y periodista austro-húngaro Karoly M. Benkert, quien invocó la combinación de una raízetimológica griega ("homo" por "igual") y una terminación latina ("sexus", "sexo"). La creación de la palabra tenía por objeto solicitar al gobierno que no penalizara a las personas de igual sexo implicadas en una relación erótica o sexual entendiendo que un acto consensuado y privado no podía dar lugar a una intervención criminalizante. Para dar fundamentos inapelables sobre la inevitabilidad de las relaciones homosexuales, el autor señaló que la misma era innata. Begoña Enguix Grau problematiza esta historia del uso de la palabra homosexual, para reflexionar sobre la construccion, a partir de ella, de una nueva identidad basada en la interaccion entre la dominacion y la posibilidad de subvertirla. Y dice, a propósito de Benkert, que:

"Hacia mediados del siglo XIX, la homosexualidad ya está bien caracterizada como enfermedad, por lo que hay que considerar la definición de Benkert como la culminación de un proceso y no como el inicio del mismo" (Enguix Grau, 2000).

A partir de allí, en unos pocos años, junto al correlativo ("der Heterosexuelle") ganó una gran aceptación el uso popular del concepto. También, se extendió en el ámbito médico legal, pero sin el sentido positivo con que su creador lo había dotado. Recién en 1973, la Asociación Norteamericana de Psiquiatría la eliminó como enfermedad del grupo de las "desviaciones sexuales" y, en 1990, hizo lo propio la Organización Mundial de la Salud (Gemetro, 2009, p. 9).

Las transformaciones en materia de género y sexualidades a lo largo del siglo XIX XX fueron analizadas desde distintas perspectivas. El historiador Eric Hobsbawm (1996) precisa que hubo: 
"Importantes cambios en las actitudes públicas acerca de la conducta sexual, la pareja y la procreación, tanto oficiales como extraoficiales, los más importantes de los cuales pueden datarse, de forma coincidente, en los años sesenta y setenta. Oficialmente ésta fue una época de liberalización extraordinaria" (p. 324).

Hobsbawm evalúa que las demandas en pos de derechos sexuales y reproductivos no parecían organizadas ni interesadas en un modo de expresión colectivo más amplio, sino que respondían a intereses de expresividad más espontáneos y anárquicos. Pablo Ben, por el contrario, considera que, en aquellos años convulsionados de grandes movimientos libertarios como el Mayo Francés (1968), el "prohibido prohibir" se generalizó a movimientos de todo tipo:

"La cultura hippie se oponía a una sociedad bélica, al igual que el movimiento contra la guerra de Vietnam. El feminismo radical luchaba por la liberación de las mujeres. Las Panteras Negras demandaban el fin de la opresión racial contra la población negra" (Ben, 2008).

En ese marco se dieron los acontecimientos de Stonewall Inn, un bar donde se reunían personas de identidades no heterocisnormativas que era allanado habitualmente y terminaba con detenciones. El 28 de junio de 1969 hubo una redada en la que se intentó detener a varias personas. Sin embargo, las personas que quedaban en el bar y otras que se fueron sumando, se resistieron con éxito a que ello sucediera. Para Pablo Ben, sin duda, Stonewall "no se limitó a ser una mera escaramuza, sino que adquirió miras más amplias" y se convirtió en el origen de un movimiento GLTTTBI creciente que llevó a que miles de organizaciones surgieran en EEUU (Ben, 2008). ${ }^{12}$ También tuvo efecto en otros espacios nacionales. ${ }^{13}$

Algunos cientistas sociales sostienen que, actualmente, asistimos a la agonía de aquel ecumenismo social homosexual y observamos el levantamiento del mundo de la distinción gay, es decir, de una demanda de inclusión general a una configuración identitaria separatista. En este sentido, Ernesto Meccia (2008) cuestiona el modo en que los circuitos capitalistas y los medios de comunicación generan una saturación "miope" a la hora de representar la homosexualidad y una retahíla de sentidos

12 Una interpretación clásica sobre la importancia del estallido en D' Emilio (2006). Cabral (2009) considera que esta idea de heterogeneidad sexual en el nacimiento de Stonewall es más bien mítica, aunque aboga por que sea realidad. Una reflexión política sobre las alianzas entre feminismos y disidencias, en Saxe (2019).

13 Así, Karina Felitti señala que, en Argentina, se conformó en agosto de 1971 el Frente de Liberación Homosexual de la Argentina (FLH) que incluía a varones gay, algunos de los cuales habían participado de una experiencia de organización previa, Nuestro Mundo, en 1967. El FLH tuvo puntos de lucha comunes con el feminismo local de esos años. Véase Felitti (2004-2005) y Simonetto (2017). 
públicos sobre la "identidad gay" que, en muchos casos, desdibuja las prácticas a través de caricaturas grotescas.

A ello se suman el impulso de sectores políticos que, desde diferentes posiciones, promueven políticas rosas ${ }^{14}$ que buscan generar una imagen de inclusión a través de la reproducción más burda del sistema de explotación. La educación sexual, como lo han planteado numerosos estudios, ha atravesado la historia de América Latina (Balderston y Guy, 1998; Theumer, 2017). El debate abierto por nuevas miradas sobre el tema ha generado una enorme diversidad en el estado legislativo y las políticas públicas en el continente; y se desarrolló tanto una actualización como una ampliación de sentidos en la comprensión, así como también, el recrudecimiento de los disciplinamientos tras los giros neoliberales (Esquivel, 2013; Torres, 2014; Esquivel y Alonso, 2015; Báez, 2020; Morán Faúndes, 2015; Vaggione, 2010).

Asimismo, al calor de distintas líneas, se han plasmado reflexiones originales para repensar la problemática, como pueden considerarse los aportes de Guacira Lopes Louro quien, entre otros valiosos aportes, acuñó el concepto de "pedagogías de la sexualidad" (1999; 2019).

"Las investigaciones de Lopes Louro describen los modos en que 'estar' en la escuela impone a niñxs y jóvenes determinados comportamientos considerados naturales, en el marco de una empresa dirigida a discernir cuánto lxs estudiantes se aproximan o apartan de la norma deseada" (Seoane y Severino, 2019, p. 1).

En la Argentina, desde los albores del siglo XX, distintas personas, organizaciones políticas, sociales, profesionales y los propios gobiernos se preocupan por educar con clivajes de género, y también, énfasis en la sexualidad (Balderston y Guy, 1998). El eje de acción de estas propuestas no estaba enfocado en la escolaridad sino en el conjunto de las personas, especialmente de las más jóvenes y en edad reproductiva. Dentro de la historiografía argentina, existen cuantiosos trabajos que evidencian las diferentes iniciativas gestadas desde espacios institucionales y culturales (Ben, 2000; Scharagrodsky, 2008; Rustoyburu, 2012; Salessi, 1995; Nari, 2004; Miranda, 2011;Biernat y Ramacciotti, 2013; Lavrin, 2005; Miranda y Vallejos, 2007; Felitti, 2012; Puiggrós, 1990; Cosse, 2010). Aquí, solo mencionaremos algunas características comunes. Estas iniciativas tuvieron una mirada eugenésica y/o higienista que procuraban la prevención de infecciones y enfermedades en función de asegurar la reproducción sana de la población, estaban generizadas en términos binarios -es decir, proponían algunas líneas de acción para las mujeres y otras, para los varones en función de los pares duales antes repuestos-y eran normalizadoras y patologizantes.

14 La expresión en inglés es "pinkwashing". Hace referencia a este tipo de políticas tomadas por empresas, instituciones o el propio Estado. 
Otros trabajos se han encargado de recuperar los proyectos orientados a educar la sexualidad que se gestaron desde espacios y miradas alternativas 0 contrahegemónicas. Algunos de ellos, destacando la presencia de mujeres que se desempeñaron en diferentes ámbitos de la educación formal e informal (Morgade, 1997; Lionetti, 2007; Carli, 2011; Southwell, 201l; Puiggrós, 1990; Lavrin, 2005; Nari, 2004). En este mismo rumbo, el anarquismo es un caso paradigmático. Este movimiento dedicó tempranamente parte de sus esfuerzos a esta dimensión del problema social de la sexualidad (Barrancos, 1990) y evidenció el placer como aspecto a considerar (Ledesma Prietto, 2016; Fernández Cordero, 2017).

Sin duda, el estudio de Lucía Lionetti (2007) contribuye a pensar los aportes señalados al analizar los discursos pedagógicos sobre educación de la sexualidad en la Argentina de las primeras décadas del siglo XX. La autora desgaja de qué modo la eugenesia y los supuestos científicos del momento operaron en un amplio abanico de figuras que incluyen a Raquel Camaña, Víctor Mercante, Julio Barcos y Aníbal Ponce. En sus obras, se propusieron pensar e intervenir en la etapa de la pubertad a fin de evitar "desvíos morales y patologías sexuales" en un momento vital que consideraban clave en la formación de los seres humanos.

La segunda mitad del siglo XX, caracterizada por un resplandor de la juventud y pautas culturales que buscaban ablandar los márgenes de la moralidad, también en el plano sexual, se promovieron cuantiosas iniciativas vinculadas a la educación de la sexualidad. La mayoría de los estados latinoamericanos estuvieron, por entonces, signados por la interrupción de los sistemas democráticos y la instauración de regímenes militares autoritarios que se cimentaban en valores patrióticos, cristianos y de revaloración de la familia tradicional. Paralelamente, los organismos internacionales comenzaron a preocuparse por relevar datos y planificar acciones para controlar el crecimiento demográfico en zonas subdesarrolladas, como las de América Latina.

Paola Dogliotti nos introduce en el caso uruguayo para delinear de qué modo las distintas variantes de la gimnasia operaron para establecer modelos, prácticas y referencias específicas en términos de cuerpos masculinos y femeninos y las expectativas en torno a éstos. La gimnasia femenina inscribió a las mujeres en un modelo corporal contrapuesto con el de los varones, que eran considerados, finalmente, referentes. Ese modelo corporal estuvo en el orden de lo abyecto y las "otredades" donde, además de las mujeres, se inscribía a los homosexuales, las mujeres viriloides, los afeminados, entre otras figuras. También aquí, como en el texto de Lionetti, se aprecian notas eugénicas y bases biologicistas, con algunos matices.

Nilia Viscardi, Leonel Rivero, Clarisa Flous, Malena Zunino y Verónica Habiaga evidencian, para el caso uruguayo, de qué modo se produce un pasaje en la educación sexual desde el paradigma médico-sanitario hacia el de los derechos políticos asociados a la identidad y la diversidad, momento este último que denominan durante el ciclo progresista (2005-2019). Desde 2020, la avanzada neoliberal, cada vez más y 
mejor organizada, coloca en términos de afrenta la idea de la ESI, la etiqueta como parte de una ideología de género, que se propone revertir un orden natural que, al fin y al cabo, no debe inmutarse.

La Argentina, como ha señalado Karina Felitti (2012), estaba lejos de tener un problema de crecimiento demográfico, contaba con bajas tasas de natalidad e inició tempranamente en el siglo XX su transición demográfica. Santiago Zemaitis (2016) brinda una lograda síntesis bibliográfica sobre estas temáticas:

"Entre las décadas de 1970 y 1980, se fueron desarrollando en el marco de propuestas no gubernamentales, varias instituciones internacionales de estudio e investigación destinadas a la formación de la sexualidad y la salud sexual, en las cuales Argentina ha formado parte. Puede mencionarse, por ejemplo, la creación en 1975 del Comité Regional de Educación Sexual para América Latina y el Caribe (CRESALC) con el apoyo de la Agencia Sueca para el Desarrollo Internacional; entidad que tendrá un rol fundamental en la formación de educadores sexuales en la región y en la Argentina" (p. 42).

Durante ese período, se forman y funcionan en América Latina y en la Argentina distintas entidades, con fondos privados o de organismos internacionales, destinadas a la investigación, la formación de profesionales y la atención de personas en temas vinculados a la sexualidad.

La década de 1980 estará signada por distintas convenciones, acuerdos y declaraciones internacionales en función de los derechos de las infancias y las mujeres. Estas enunciaciones destacan la importancia de la educación para la efectivización de otros derechos y para la prevención de violencias, enfermedades, etc., así como la injerencia y responsabilidad de los Estados para el cumplimiento de estos derechos. Durante ese mismo período, la circulación del Virus de la Inmunodeficiencia Humana $(\mathrm{VIH})$ encendió un estado de alarma en los sectores de salud, pero especialmente en aquellos vinculados a la educación -ya que la prevención continúa siendo, hasta la actualidad, la principal línea de trabajo en torno a esta cuestión-. En el caso de la Argentina, este contexto internacional se ve potenciado por la recuperación de las instituciones de la democracia, la efervescencia de las culturas juveniles y la ruptura de las pautas conservadoras y moralistas, que también en sexualidad había impuesto la última dictadura militar (1976-1983) a través de un sinnúmero de dispositivos de disciplinamiento (D'Antonio, 2016). En esos mismos años, la ciudad de Buenos Aires se convertirá en la primera jurisdicción en contar con una ordenanza referente a la educación sexual (Ordenanza 40.089/84) la cual crea en la Escuela Superior de Capacitación Docente el curso de Educación Sexual. Hacia el final de la década también inaugurarán, en 1988, el Programa de Procreación Responsable.

La siguiente década abrirá varias posibilidades para la educación sexual. En 1990, se sanciona la Ley Nacional de SIDA -reglamentada bajo el Decreto 1.244/91- cuyo 
espíritu alienta la educación como forma de evitar la propagación de la enfermedad. En 1992, Santa Fe será la primera provincia en sancionar una ley de educación sexual, que además incluía una propuesta interdisciplinaria. Aunque, como bien advierte Juan Cruz Esquivel (2013), la sanción de la normativa no es garantía de su aplicación:

"La Ley Federal de Educación, aprobada en 1993, contempló a la sexualidad como contenido curricular. Propuesta su inclusión de modo transversal, su inserción efectiva se tornaba inespecífica. Apenas algunas jurisdicciones diseñaron políticas de capacitación hacia los docentes. Por ejemplo, en la ciudad de Buenos Aires, se organizaron talleres formativos, con una marcada impronta biomédica. Los contenidos giraban en torno a la prevención de enfermedades de transmisión sexual, las metodologías de enseñanza sobre las partes del cuerpo y las funciones reproductivas" (p. 40).

Es interesante reflexionar sobre acontecimientos como la Ley Federal de Educación, que ha trascendido en los imaginarios docentes, sindicales y en la bibliografía sobre la historia de la educación como un hecho nefasto. A pesar de ello, y sin quitarle espacio a los efectos nocivos que causó sobre el sistema educativo, sus trabajadorxs y lxs educando de todos los niveles, esta ley generó precedentes en varias cuestiones, como señala Esquivel. Algo similar ocurre con la reforma constitucional de 1994, que dio rango constitucional a varios tratados internacionales, como la Convención sobre los Derechos del Niño. Claro que los fines de entonces mixturaban objetivos diversos en términos ideológicos; sin embargo, posteriormente, normativas como la Ley Nacional de ESI se apoyaron en esa convención para su fundamentación.

En los siguientes años de esa década y en los primeros lustros del nuevo milenio, distintas provincias sancionaron normativas, de diferente jerarquía, pautando algunas líneas en salud sexual y reproductiva y, también, en educación sexual. Si bien actualmente contamos con una Ley Nacional de Educación Sexual Integral que, posteriormente, fue ratificada e incluso empleada por algunas provincias Buenos Aires lo hace en 2015-, otras provincias continúan sin realizar este proceso. Este movimiento del centro hacia las periferias sería inverso a lo que Esquivel evidencia en la etapa anterior al 2006 cuando "Las iniciativas en el campo de la salud sexual y reproductiva fueron de la periferia al centro, de las provincias a la nación" (Esquivel, 2013, p. 41).

El estudio de Esquivel (2013), al que hicimos referencia, reconstruye minuciosamente el escenario nacional $y$, en particular, el de la provincia de Buenos Aires y CABA mostrando cómo la entrada de la sexualidad a las escuelas estuvo estrechamente ligada a las leyes de salud reproductiva y procreación responsable. También, muestra cómo estos ingresos tomaron una línea vinculada a la biología y no tan centrado en el paradigma de la ciudadanía, en el cual se focalizarán posteriormente y hasta la actualidad. En el caso de la provincia de Buenos Aires, particularmente en La 
Plata, el autor detalla las vicisitudes planteadas en el área de la gestión privada de la educación, específicamente con las escuelas confesionales, a partir de los posicionamientos de las autoridades eclesiásticas y la influencia que estas posturas tuvieron sobre las autoridades provinciales.

Como señala Eleonor Faur (2020), la puja entre la concepción de los movimientos en pos de los derechos sexuales -reproductivos y no reproductivos-y la Iglesia ha sido siempre desigual y a favor de la Institución eclesiástica, aunque en ese desequilibrio de fuerzas, el Estado asume un papel clave puesto que "la orientación de las políticas públicas gravitará en la posición que asuma el Estado. La decisión es política" (p. 227). Asimismo, otros estudios consignan que ha habido, en materia de políticas sexuales, resquebrajaduras dentro de las propias iglesias mostrando posiciones alternativas respecto de los derechos sexuales y reproductivos, educación sexual, matrimonio igualitario y aborto (Pecheny, Jones y Ariza, 2016, pp. 206-207). Como señala Josefina Leonor Brown (2009), las discusiones plantean las lógicas de la escisión y porosidad de lo público y lo privado, sobre cómo convertir lo particular, singular, en materia de sexualidad; en "un asunto de escucha universal":

"Uno de los mayores desafíos de los movimientos políticos que aúnan fuerzas en torno de la conquista de derechos (no) reproductivos y sexuales tendientes a la consecución de cierta justicia erótica" (p. 26).

En la Argentina, a partir de la sanción de la Ley Nacional de ESI (como ya mencionamos del año 2006) se han publicado y presentado en jornadas, congresos y otros eventos académicos y educativos numerosísimos trabajos que recopilan y son parte de lo que ha sucedido en este campo desde entonces. Libros, artículos, ponencias, entre otros productos, muestran el trabajo desplegado por instituciones 0 personas que denuncian el incumplimiento de la normativa y las trabas institucionales para la efectiva implementación, que muestran el lugar biologicista donde muchas veces sigue anclada la práctica educativa, ${ }_{1}^{15}$ que reclaman la actualización de los lineamientos curriculares (2009) en función de dejar atrás el binarismo y pensar la identidad de manera aún más diversa. Como señala Alba Rueda (2020):

"El material de ESI, la ley y su Programa no cuenta con información precisa ni aborda las diferencias de relaciones de poder que oprimen a las personas travestis y trans, tampoco propone herramientas pedagógicas para abordar la violencia en nuestros recorridos de vida y especialmente en las instituciones educativas" (p. 260).

15 Sin pretender exhaustividad, algunos aportes en este sentido pueden consultarse en Elizalde (2014). 
Es necesario, como dice Rueda, deshetereronormativizar la ESI. En ese plan, la apuesta de Luciana Lavigne y Juan Péchin evidencia la interrelación entre los movimientos feministas y de la disidencia sexual en relación con la apuesta política que supuso la ESI en términos de movimiento pedagógico. Recuperan los clivajes epistemológicos que nutren las reflexiones y prácticas de los activismos de género y el modo en que cuestionan el binarismo sexo-genérico que, en muchos sentidos, todavía sustentan el sistema educativo argentino ${ }^{16}$. Parte de los trabajos que presentamos en esta publicación avanzan en esta línea, reponen ellos mismos, son parte de este ir haciendo que nos propone la investigación acción. Hacer, reflexionar sobre el hacer y compartir con la comunidad académica y educativa ese recorrido.

"Senderos Transitados en la construcción de un ideario institucional para una mejor Educación Sexual Integral", de Manuela Almirón y Mónica Fernández, nos muestra la intervención institucional que realizó un Jardín de Infantes de Florencio Varela para implementar la ESI. Las múltiples tareas que realizó el personal de la institución, las articulaciones con otras instituciones y, especialmente, el vínculo que pudieron generar con la comunidad donde está emplazado el Jardín. Muchxs jardines y docentes del nivel inicial ven aún como gran desafío el trabajo con la ESI, sin negar que lo sea, trabajos y experiencias como las que nos narran Manuela y Mónica nos muestran que la ESI, pensada desde las instituciones para la comunidad y con la comunidad, es una posibilidad para revitalizar ese vínculo.

El siguiente artículo es el de Cecilia Linare, Lucas Bruschetti y Daniela Casi, titulado "Polifonías docentes. Educación Sexual Integral en el nivel primario bonaerense, ¿ausencias, resistencias o invisibilidades?". Este texto es parte de un trabajo mayor que se está llevando a cabo en la región educativa $N^{\circ} 1$ de la provincia de Buenos Aires. Mediante una pequeña muestra, lxs autorxs avanzan sobre una de las grandes carencias carencias en el campo de investigación en torno a la ESI: La sistematización de experiencias.

El trabajo de Milagros Rocha completa el panorama por los niveles educativos obligatorios en la Argentina. "Mujeres y género en la enseñanza de la historia. Reflexiones y propuestas en diálogo con la ESI" hace jugar dos campos disciplinares en constante crecimiento, el de la Historia de las mujeres y los Estudios de Género, con la Historia enseñada en la escuela secundaria y la manera en que desde estos aportes se puede abordar uno de los aspectos de la ESI, el disciplinar. Además, la autora recupera una experiencia, convertida ya en referencia, de las luchas por la implementación de la ESI en donde lxs estudiantes encabezan el reclamo, sintetizado en la frase"¿Dónde está mi ESI?". El trabajo concluye con un generoso aporte: un

16 Los trabajos de val flores sobre ESI también avanzan sobre esta cuestión (2019; 2020). 
análisis en clave de género de los diseños curriculares del nivel, algunas experiencias docentes y una caja de herramientas de gran utilidad para quienes nos dedicamos a la enseñanza de la Historia. Además de los aportes teóricos y analíticos necesitamos, para la efectiva implementación de la ESI, producción que nos proporcione insumos para la formación y el trabajo cotidiano. Hace apenas tres años y como fruto del trabajo colectivo de estudiantes y docentes se publicó un libro que compila el trabajo de muchos años sobre matrices de derechos y género, que contiene actualizaciones teóricas y secuencias didácticas para el abordaje de las Ciencias Sociales con perspectiva de género en el aula (Gorza y Valobra, 2018).

El dossier concluye con un breve texto, "Apuntes sobre la experiencia de un concurso de producciones con temática de género para estudiantes de secundario, de Ariadna Quiroga y Facundo Saxe, que narra la experiencia de pensar, organizar y realizar dos emisiones del Concurso de Producciones con Temática de Género (2016 y 2017) destinado a jóvenes de la escuela secundaria. El concurso fue organizado desde el Centro Interdisciplinario de Investigaciones en Género (CInIG-IdIHCS) y la Facultad de Humanidades y Ciencias de la Educación de la Universidad Nacional de La Plata. Como muestra de los saberes y afectos construidos, reproducimos los dos cuentos que ganaron cada una de las emisiones mencionadas: Malena sin voz, de Abril Castro; y Metamorfosis, de Guido Sanz. Los cuentos permiten vibrar, emocionarse y conocer las perspectivas de las generaciones más jóvenes que construyen un sentido de la Educación Sexual Integral que puede y debe ser considerado (Tomasini, 2020). Como señala Alba Rueda (2020), se trata de "resignificar la propuesta de la ESI, restituir la fuerza docente y estudiante frente a las dificultades en la implementación masiva y sistemática del Programa de ESI" (p. 261).

Esperamos que los artículos que conforman el dossier sean un valioso aporte a los campos de estudio sobre la educación, las sexualidades y la manera en que estas se entrelazan y contribuyen a profundizar y problematizar la implementación de la Educación Sexual Integral en las escuelas de manera democrática, diversa, sin viejas ni nuevas moralidades y con participación estudiantil.

\section{Consideraciones finales}

El aporte que nos hemos propuesto con este dossier convive con un sinfín de producciones realizadas por académicxs que estudian estos temas, por grupos de investigación generalmente vinculados a universidades, por docentes que valientemente incursionan en el mundo de la producción académica, por activistas vinculadxs a experiencias de educación formal y no formal y en la mayoría de los casos, por personas que conjugan varias de estas pertenencias. Esos trabajos describen y analizan entre otras cosas: capacitaciones, propuestas institucionales, proyectos de extensión y articulación, propuestas áulicas, enfoques disciplinares para los diferentes niveles, etc. El número, afortunadamente, es tan grande que sería imposible sintetizarlos. 
Sin embargo, otros aspectos de estas normativas y de su aplicación siguen siendo una zona gris, faltan aún trabajos sistemáticos que muestren cómo aprenden los contenidos vinculados con la ESI las infancias, las juventudes y, también, las personas adultas. En este sentido varios grupos de trabajos se encuentran abocados a la construcción de pedagogías y didácticas "propias" de la ESI -donde se toman numerosos enfoques de la educación popular, la educación no formal y la psicología social- que muchas veces entran en disputas con otras especialidades, generando acalorados debates en el ámbito educativo. Las Universidades, en ese sentido, si bien impulsan iniciativas a través de talleres estudiantiles y de extensión a la comunidad, no parecen haberse conmovido cualitativamente en relación con sus propias currículas y espacios institucionales, más allá de la aparición de espacios de género en el organigrama y del desarrollo de ciertas capacitaciones devenidas de la Ley Micaela.

Faltan, asimismo, trabajos estadísticos que nos acerquen un panorama cuantitativo de lo que sucede en las distintas instancias del sistema educativo, aunque esperamos que la reciente creación del Observatorio Federal de ESI pueda reponer parte de esta información -con lo que, posteriormente, podremos construir datos y elaborar análisis-. Faltan aún propuestas para transversalizar la ESI desde lo curricular, sin ser ampliaciones sumativas de contenidos (algunas áreas han logrado avanzar en esta tarea -entre ellas especialmente las ciencias sociales). Faltan trabajos que sistematizan las repercusiones en la vida institucional de las escuelas a partir de la implementación de la ESI. Quedan, también, aún por hacerse análisis profundos y comparativos de los debates legislativos y de los tratamientos en comisión que dieron origen a estas leyes, tanto en la nación como en las provincias para conocer los debates y fundamentos esgrimidos y comprender, más cabalmente, el espíritu de la ley que impulsó las normas. Y, finalmente, necesitamos más investigación a escala regional, para pensar las características de esta región del mundo y, también, las particularidades de zonas y comunidades que muchas veces no se corresponden con las fronteras de los Estados nacionales. Es necesario, finalmente, en este siglo XXI, repreguntarnos sobre la vigencia, los matices, las problematizaciones o los nuevos sentidos que debemos darnos en torno a premisas históricas sobre la "disidencia" sexo-genérica. Repreguntarnos, por ejemplo, que es lo que nos hace disidir de lo que Adrienne Rich caracterizó como la institución política de la heterosexualidad obligatoria.

\section{Bibliografia}

Abbate, F. (2020). Biblioteca feminista. Vidas, luchas y obras desde 1789 hasta hoy. Buenos Aires: Planeta.

Ariza, L. (2018). Más acá o más allá de la diferencia sexual. Para una epistemología feminista alternativa a través de Elizabeth Grosz y Myra Hird. Descentrada, 2(2). 
Recuperado de https://www.descentrada.fahce.unlp.edu.ar/article/view/ DESe048/9750

Badinter, E. (1993). XY, la identidad masculina. Bogotá: Norma.

Cabral, M. (26 de junio de 2009). "Todas las manos, todxs". Suplemento Soy, Página 12. Recuperado de http://www.paginal2.com.ar/diario/suplementos/soy/1-8322009-06-28.html

Báez, J. (2020). Escenas contemporáneas de la educación sexual en Latinoamérica: Una lectura en clave feminista. Mora, (25), pp. 219-226. https://doi.org/10.34096/mora.n25.8533

Barrancos, D. (1990). Anarquismo, educación y costumbres en la Argentina de principios de siglo. Buenos Aires: Contrapunto.

Balderston, D. y Guy, D.J. (Comps). (1998). Sexo y sexualidades en América Latina. Buenos Aires: Paidós.

Ben, P. (2000). Muéstrame tus genitales y te diré quién eres. El "hermafroditismo" en la Argentina finisecular y de principios de siglo XX. En O. Acha y P. Halperín (Comps.). Cuerpos, géneros e identidades. Buenos Aires: Ediciones del Signo.

Ben, P. (27 de junio de 2008). Stonewall -y la rebelión del orgullo-, Suplemento Soy. Página 12. Recuperado de https://www.paginal2.com.ar/diario/suplementos/ soy/1-157-2008-06-27.html

Ben, P. (2020). Foucault, capitalismo y sexualidad: tensiones conceptuales circa 1976. Mora, (25), pp. 63-84. https://doi.org/10.34096/mora.n25.8492

Biernat, C. y Ramacciotti, K. (2013). Crecer y multiplicarse: La política sanitaria maternoinfantil argentina 1900-1960. Buenos Aires: Biblos.

Bilinkis, M. (2014). Niñez y sexualidad infantil. Los debates parlamentarios de la Ley Nacional de Educación Sexual Integral. En A. Castro Esnal et al. (Eds.), Entre pasados y presentes IV: estudios contemporáneos en ciencias antropológicas. Buenos Aires: Asociación Amigos del Instituto Nacional de Antropología.

Bock, G. (1991). La historia de las mujeres y la historia del género: aspectos de un debate internacional. Revista de Historia Social, (9), pp. 55-77.

Boris, E. (2020). De las mujeres al género y más allá: las entretejidas trayectorias de la historia de las mujeres y los estudios feministas. Mora, (25), pp. 45-56. https://doi. org/10.34096/mora.n25.8490

Brown, J.L. (2009). Los derechos (no) reproductivos y sexuales en los bordes entre lo público y lo privado. Algunos nudos del debate en torno a la democratización de la sexualidad. Sexualidad, Salud y Sociedad - Revista Latinoamericana, (2), pp. 10-28 Recuperado de https://www.redalyc.org/articulo.oa?id=293322969002 
Cabral, M. (2007). "Intersexualidad" y "Transgénero". En S. Gamba (Coord.), Diccionario de estudios de género y feminismo (pp. 325-327). Buenos Aires: Biblos.

Cabral, M. (26 de junio de 2009). Todas las manos, todxs. Suplemento Soy. Página 12. Recuperado de http://www.paginal2.com.ar/diario/suplementos/soy/1-8322009-06-28.html

Campagnoli, M. (2018). Epistemologías críticas feministas. Aproximaciones actuales. Descentrada, 2(2). Recuperado de https://www.descentrada.fahce.unlp.edu.ar/ article/view/DES047/9808

Ciccia, L. (2018). La dicotomía de los sexos puesta en jaque desde una perspectiva cerebral. Descentrada, 2(2). Recuperado de http://www.descentrada.fahce.unlp. edu.ar/article/view/DESe052

Connell, R. (1997). La organización social de la masculinidad. En T. Valdés y J. Olavarría (Comps.), Masculinidad/es. Poder y crisis. Santiago de Chile: Ediciones de las Mujeres-Isis Internacional, № 24, pp. 77-89. Recuperado de http://joseolavarria.cl/ wp-content/uploads/downloads/2014/08/Masculinidad-poder-y-crisis-Valdesy-Olavarria.pdf

Cosse, I. (2010). Pareja, sexualidad y familia en los años sesenta. Una revolución discreta en Buenos Aires. Buenos Aires: Siglo XXI.

D'Antonio, D. (2016). La prisión en los años 70. Historia, género y política. Buenos Aires: Biblos.

D'Emilio, J. (2006). Capitalismo e identidad gay. Nuevo Topo, 2. http://issuu.com/ nuevotopo/docs/04-art_culo_john_d_emilio_nt2

Elizalde, S. (2013). Articulaciones entre género, sexualidad y edad en los estudios de juventud: presupuestos ideológicos y operaciones de la crítica. Sudamérica: Revista de Ciencias Sociales, 2(2), pp. 21-35. Recuperado de https://fh.mdp.edu.ar/revistas/ index.php/sudamerica/article/view/855/874

Elizalde, S. (2014). Aprendiendo a ser mujeres y varones jóvenes: prácticas de investimento del género y la sexualidad en la institucionalidad escolar. Intersecciones en Comunicación, l, pp. 33-52. Recuperado de https://ri.conicet.gov.ar/bitstream/ handle/11336/45848/CONICET_Digital_Nro.41c91758-de61-434a-a4fa29817 bf58dee_A.pdf? sequence=2yisAllowed $=y$

Elizalde, S., Felitti, K.y Queirolo, G. (Coords.). (2009). Género y sexualidades en las tramas del saber. Revisiones y propuestas. Buenos Aires: Libros del Zorzal.

Enguix Grau, B. (2000). Sexualidad e identidades. Identidades homosexuales. Gazeta de Antropología, (16), pp. 1-8. Recuperado de https://www.ugr.es/ pwlac/ G16_04Begona_Enguix_Grau.html 
Esquivel, J.C. (2013). Mediaciones y disputas político-religiosas como condicionantes de la educación sexual en la ciudad de Buenos Aires. Estudios Sociológicos, 31(92), pp. 369-395.

Esquivel, J.C. y Alonso, J.P. (2015). Actores y discursos religiosos en la esfera pública: los debates en torno a la educación sexual y a la "muerte digna" en Argentina. Sexualidad, Salud y Sociedad. Revista Latinoamericana, (21), pp. 85-110.

Faur, E. (2020). La Catedral, el Palacio, Las aulas y la calle. Disputas en torno a la Educación Sexual Integral. Mora (25), pp. 227-234. https://doi.org/10.34096/mora.n25.8534

Felitti, K. (2004-2005). La política demográfica del tercer gobierno peronista:justificaciones, repercusiones y resistencias a las restricciones al control de la natalidad (1973-1976). Trabajos y Comunicaciones (Segunda época), (30/31), pp. 288-307.

Felitti, K. (2012). La revolución de la píldora. Sexualidad y política en los sesenta. Buenos Aires-Barcelona: Edhasa.

Femenías, M. L. (2008). Simone de Beauvoir: hacer triunfar el reino de la libertad. Oficios Terrestres, 21, pp. 32-45.

Fernández, A. (1992). La sexualidad atrapada de la señorita maestra. Buenos Aires: Nueva Visión.

Fernández Cordero, M.L. (2017). Amor y Anarquismo. Experiencias pioneras que pensaron y ejercieron la libertad sexual. Buenos Aires: Siglo XXI.

Fiocchietto, R. (1987). La amante celeste. La destrucción científica de la lesbiana. Madrid: Estro Editrice.

flores,v. (2019).¿Eslaprácticapedagógicauna prácticasexual? Umbrales delaimaginación teórica y erótica. Descentrada, 3(1). https://doi.org/10.24215/25457284e068

flores, v. (2020). El derecho al gemido. Notas para pensar la ESI desde una posición prosexo. Mora, (25), 249-254. https://doi.org/10.34096/mora.n25.8537

Foucault, M. (1991). Historia de la sexualidad, La voluntad de saber. México. Siglo XXI.

Fox Keller, E. (1991). Reflexiones sobre género y ciencia. Valencia: Alfons El Magnànim.

Gay, P. (1984a). La experiencia burguesa. De Victoria a Freud (2 Tomos). México: Fondo de Cultura Económica.

Gay, P. (1984b), La experiencia burguesa. De Victoria a Freud (Tomo 1: La Educación de los sentidos). México: Fondo de Cultura Económica.

Gemetro, F. (2009). Lesbianismo, homosexualidad femenina y homosexualidad. reflexiones críticas sobre el uso sociológico de los términos en la Argentina. Ponencia presentada en XXVII Congreso de la Asociación Latinoamericana de Sociología, VIII 
Jornadas de Sociología de la Universidad de Buenos Aires. Asociación Latinoamericana de Sociología, Buenos Aires, Argentina.

Giddens, A. (1992). The Transformation of Intimacy. Sexuality, Lovey Eroticism in Modern Societies. California: Stanford University.

Gómez Rodríguez, A. (2005). Ciencia y valores en los estudios del cerebro. Arbor, (716), pp. 478-492.

Gonzáles García, M.I. (2005). Valores de una ciencia impura. Arbor, (716), pp. 501-514.

González del Cerro, C. (2020). La educación sexual integral ¿es feminista?. Mora, (25). Recuperado de http://revistascientificas.filo.uba.ar/index.php/mora/issue/ view/657

Gorza, A. y Valobra, A. (Eds.). (2018). Género y derechos: Una propuesta transformadora para el aula de Ciencias Sociales. La Plata: Universidad Nacional de La Plata. Facultad de Humanidades y Ciencias de la Educación-Andamios-. Serie Materiales. Recuperado de https://libros.fahce.unlp.edu.ar/index.php/libros/catalog/book/

Guerra, L. y Sciortino, S. (2013). Volver a los setenta: el feminismo italiano de la diferencia sexual. La Plata: EdULP.

Haraway, D. (1993). Saberes situados: el problema de la ciencia en el feminismo y el privilegio de una perspectiva parcial. En M.C. Cangiano y L. Dubois, De mujer a Género. Teoría, interpretación y práctica feminista en las ciencias sociales. Buenos Aires: CEAL.

Hobsbawm, E. (1996). Historia del siglo XX. Barcelona: Crítica.

Iglesias Aparicio, P. (2003). La mujer según la ginecología del siglo XIX. En Mujer y salud: las escuelas de medicina de mujeres de Londres y Edimburgo (Tesis doctoral). Facultad de Filosofía y Letras, Universidad de Málaga. Disponible en https://riuma. uma.es/xmlui/bitstream/id/1293/16272791.pdf

Kaufman, M. (1995). Los hombres, el feminismo y las experiencias contradictorias del poder entre los hombres. En L. Arango, L., M. León y M. Vivero (Comps.), Género e identidad. Ensayos sobre lo femenino y lo masculino (pp. 123-146). Bogotá: Uniandes/ Tercer Mundo Editores.

Kimmel, M. (1997). Homofobia, temor, vergüenza y silencio en la identidad masculina". En T. Valdés y J. Olavarría (Eds.), Masculinidad/es: poder y crisis (pp. 49-62). Buenos Aires: ISIS-FLACSO-Ediciones de las Mujeres $N^{\circ} 24$. Disponible en http://joseolavarria.cl/ wp-content/uploads/downLoads/2014/08/Masculinidad-poder-y-crisis-Valdesy-Olavarria.pdf

Lamas, M. (1986). La antropología feminista y la categoría "género". Nueva Antropología. 
Revista de Ciencias Sociales, (30), pp. 173-198. Recuperado de https://www.redalyc. org/pdf/159/15903009.pdf

Laqueur, T.W. (2003). Sexo solitario. Una historia cultural de la masturbación. Buenos Aires: Fondo de Cultura Económica.

Lavrin, A. (2005). Mujeres, feminismo y cambio social en Argentina, Chile y Uruguay. Santiago: Ediciones de la Dirección de Bibliotecas, Archivos y Museos.

Ledesma Prietto, N.F. (2016). La revolución sexual de nuestro tiempo: el discurso médico anarquista sobre el control de la natalidad, la maternidad y el placer sexual. Argentina, 1931-1951. Buenos Aires: Biblos.

Lionetti, L. (2007). La misión política de la escuela pública. Formar a los ciudadanos de la república (1870-1916). Buenos Aires: Miño y Dávila

Lewontin, R.C., Rose, S. y Kamin, L.J. (1987). No está en los genes. Racismo, genética e ideología. Barcelona: Crítica.

Lopes Louro, G. (1999). Pedagogías da sexualidade. En: Lopes Louro, Guacira. (comp.). 0 Corpo Educado. Pedagogías da Sexualidades (pp. 9-42), Belo Horizonte: Autentica.

Lopez Louro, G. (2019). Currículo, género y sexualidad. Lo "normal", lo "diferente" y lo "excéntrico". Descentrada, 3(1). https://doi.org/10.24215/25457284e065

Le Breton, D. (2002). Antropología del cuerpo y modernidad. Buenos Aires: Nueva Visión.

Maffía, D. (2008). Contra las dicotomías: feminismo y epistemología crítica, Seminario de Epistemología. Buenos Aires: Facultad de Filosofía y Letras-UBA, Disponible en http:// dianamaffia.com.ar/archivos/Contra-Las-dicotom\%C3\%ADas.-Feminismo-yepistemolog\%c3\%ADa-cr\%C3\%ADtica.pdf

Maffía, D. y Cabral, M. (2003). Los sexos ¿son o se hacen? En D. Maffía (Ed.), Sexualidades Migrantes, Género y Transgénero (pp. 86-97). Buenos Aires: Feminaria. Disponible en http://dianamaffia.com.ar/archivos/sexualidades_migrantes.pdf

Mariposas Mirabal. (2019). Educación Sexual Integral. Epistemología, pedagogía y política en los debates curriculares. Buenos Aires: Editorial de la Facultad de Filosofía y Letras de la Universidad de Buenos Aires. Disponible en http://repositorio.filo. uba.ar/handle/filodigital/11196

Meccia, E. (2008). Sentir que el conservadurismo es la verdadera subversión. Una propuesta sociológica para comprender el punto de vista de los últimos homosexuales. Grupo de Estudios sobre Sexualidades, Instituto de Investigaciones Gino Germani, Facultad de Ciencias Sociales de la UBA, Buenos Aires.

Miranda, M. (2011). Controlar lo incontrolable. Una historia de la sexualidad en Argentina. Buenos Aires: Biblos. 
Miranda M. y Vallejos, G. (Comps.) (2005). Darwinismo social y eugenesia en el mundo latino. Buenos Aires: Siglo XXI.

Morán Faúndes, J.M. (2015). El desarrollo del activismo autodenominado "Pro- Vida" en Argentina, 1980-2014. Revista mexicana de sociología, 77(3), pp. 407-435. Recuperado de http://www.scielo.org.mx/scielo.php?script=sci_arttextypid=S0188$25032015000300003 y$ lng=esytling=es

Moránt, I. (2018). Lecturas de El segundo sexo de Simone de Beauvoir. Descentrada, 2(2). Recuperado de https://www.descentrada.fahce.unlp.edu.ar/article/view/DESe053

Morgade, G. (Comp.). (1997). Mujeres en la educación: género y docencia en la Argentina. 1870-1930. Buenos Aires: Miño y Dávila.

Mosse, G. (1997). Hacia una nueva masculinidad. Madrid: Talasa.

Nari, M. (2004). Políticas de maternidad y maternalismo político, Buenos Aires, 18901940. Buenos Aires: Biblos.

Olsen, F. (1990). The sex of Law. En D. Kairys (Ed.), The Politics of Law. Nueva York: Panteón. Disponible en http://www.derechoshumanos.unlp.edu.ar/assets/files/ documentos/el-sexo-del-derecho.pdf

Palma, H. (2005). Gobernar es seleccionar. Historia y reflexiones sobre el mejoramiento genético en seres humanos. Buenos Aires: Baudino.

Pateman, C. (1992). "Equality, difference, subordination: the politics of motherhood and women's citizenship". En G. Bock y S. James (Eds.), Beyond equality and difference. Londres: Routledge.

Pecheny, M., Jones, D. y Ariza, L. (2016). Religion and Gender Sexual Politics and Religious Actors in Argentina. Religion and Gender, 6(2), pp. 205-225.

Puiggrós, Adriana. (1990). Sujetos, disciplina y curriculum en los orígenes del sistema educativo (1885-1916). Buenos Aires: Galerna.

Queirolo, G. (2013). Género y sexualidades en tiempos de males venéreos (Buenos Aires, 1920-1940). Revista Nomadías, (17), pp. 67-87.

Ramacciotti, K. y Valobra, A. (2008). El campo médico argentino y su mirada al tribadismo, 1936-1954. Revista de estudios feministas, 16(2), pp. 493-516. Recuperado de http:// www.scielo.br/scielo.php?script=sci_arttextypid=S0104-026X2008000200010yl ng=enynrm=iso

Rueda, A. (2020). La Educación Sexual Integral: indagaciones desde las agendas travestis trans. Mora, (25), pp. 255-262. https://doi.org/10.34096/mora.n25.8538

Rustoyburu, C. (2012). Infancia, hormonas y género: un análisis histórico de los discursos de la biotipología en Argentina en los años 1930. Sexualidad, Salud y Sociedad, (11), 
pp. 9-36.

Rustoyburu, C. y Eraso, Y. (Dirs). (2018). Cuerpos hormonales. Intersecciones entre el Laboratorio, clínica y sociedad. Mar del Plata: EUDEM.

Salessi, J. (1995). Médicos, maleantes y maricas. Rosario: Beatriz Viterbo.

Saxe, F. (2019). Nuestro Stonewall. En Cátedra Virginia Bolten (Comp.), A 50 años de Stonewall, la revuelta continúa, Fanzine de divulgación (pp. 10-15). La Plata: Cátedra Virginia Bolten y Fundación Rosa Luxemburgo.

Scharagrodsky, P. (Comp.). (2008). Gobernar es Ejercitar. Fragmentos para una historia de la Educación Física en Iberoamérica. Buenos Aires: Prometeo.

Scott, J. W. (1996). El género, una categoría útil para el análisis histórico. En M. Cangiano y L. Dubois, De Mujer a Género. Teoría, Interpretación y Práctica Feminista En Las Ciencias Sociales (pp. 17-50). Buenos Aires: Centro Editor de América Latina.

Scott, J.W. (2002). Feminismo y sufragio en Francia, 1789-1944. Buenos Aires: Siglo XXI.

Segato, R. (2003). Las estructuras elementales de la violencia: Ensayos sobre género entre la antropología, el psicoanálisis y los derechos humanos. Bernal: Universidad Nacional de Quilmes.

Seoane, V. y Severino, M. (2019). Género, sexualidades y educación. Intersecciones necesarias para una educación emancipadora. Descentrada, 3(1). https://doi. org/10.24215/25457284e063

Severino, M. y Dappello, V. (2019). Diálogos entre feminismos y educación a propósito de la ESI en Argentina. Saberes y prácticas. Revista De Filosofía Y Educación, (4), pp. 1-15. Recuperado de http://revistas.uncuyo.edu.ar/ojs3/index.php/saberesypracticas/ article/view/2213 cit

Simonetto, P. (2017). Entre la injuria y la revolución: el Frente de Liberación Homosexual. Argentina, 1967-1976. Bernal: Universidad Nacional de Quilmes. Disponible en http:// unidaddepublicaciones.web.unq.edu.ar/wp-content/uploads/sites/46/2018/04/ e-book-EntrelalnjuriaylaRevolucion-Simonetto.pdf

Smaldone, M. (2020). El rol, la praxis y las redes de las traductoras en la recepción de la obra de Simone de Beauvoir al Sur de América entre los años 1940 y 1980. Mutatis Mutandis, Revista Latinoamericana de Traducción, 13(2), pp. 255-279. Recuperado de https://revistas.udea.edu.co/index.php/mutatismutandis/issue/view/3665

Southwell, M. (2011). Lo social como interpelación pedagógica: mujeres en disputa con sus épocas. En M. Krichesky (Comp.), Pedagogía social y educación popular. Perspectivas y estudios sobre la inclusión y el derecho a la educación (Cuaderno de trabajo 2: pp. 23-36). Buenos Aires: UNIPE. 
Stolke, V. (2006). La mujer es puro cuento: la cultura del género. Desarrollo Económico, 180(45), pp. 523-546.

Tadeu da Silva, T. (1999). Documentos de Identidade: uma introdução às teorias do currículo. Belo Horizonte: Autêntica Editorial.

Theumer, E. A. (2017). Políticas homosexuales en la Argentina reciente (1970-1990s). Interdisciplina; 5(11); pp. 109-126. Recuperado de http://www.revistas.unam.mx/ index.php/inter/article/view/61329

Tomasini, M. (2020). ¿Qué mueve a las jóvenes a participar? Activismo de género y construcción de identidades en estudiantes de escuelas secundarias de Córdoba, Argentina. Psicología, Conocimiento y Sociedad, 10(2), pp. 123-149. Recuperado de https://revista.psico.edu.uy/index.php/revpsicologia/article/view/553/430

Torres, G. (2009). Normalizar: discurso, legislación y educación sexual. İconos. Revista de Ciencias Sociales, 35, pp. 31-42.

Torres, G. (2014). Una lectura de las relaciones entre Iglesia católica, Estado y educación en 30 años de democracia. Propuesta Educativa, 2, pp. 77-85.

Vaggione, J.M. (2010). El fundamentalismo religioso en Latinoamérica. La mirada de los/as activistas por los derechos sexuales y reproductivos. El activismo religioso conservador en Latinoamérica (pp. 287-318), Córdoba. Disponible en https://rdu.unc. edu.ar/bitstream/handle/11086/1837/V3_Activismo_Religioso_Vaggione_2010. pdf? sequence $=2$ yisAllowed $=y$

Zemaitis, S. (2016). Pedagogías de la sexualidad. Antecedentes, conceptos e historia en el campo de la educación sexual de la juventud. Trabajo final integrador presentado en la Universidad Nacional de La Plata, Facultad de Humanidades y Ciencias de la Educación, La Plata. Disponible en http://www.memoria.fahce.unlp.edu.ar/tesis/ te.1218/te.1218.pdf 